\title{
Propulsion Estimates for High Energy Lunar Missions Using Future Propellants
}

\author{
Bryan A. Palaszewski* \\ NASA John H. Glenn Research Center \\ Lewis Field • MS 5-10 \\ 21000 Brookpark Road $\bullet$ Cleveland OH 44135-3191 \\ Telephone: 1+216.977.7493; Fax: 1+216.433.5802 \\ E-mail: bryan.a.palaszewski@nasa.gov \\ Gary L. Bennett** \\ Metaspace Enterprises \\ 5197 West Redbridge Drive • Boise ID 83703-3431 \\ Telephone: $1+208.333 .7764$ \\ E-mail: UserSg4282@aol.com
}

High energy propellants for human lunar missions are analyzed, focusing on very advanced ozone and atomic hydrogen. One of the most advanced launch vehicle propulsion systems, such as the Space Shuttle Main Engine (SSME), used hydrogen and oxygen and had a delivered specific impulse of $\mathbf{4 5 3}$ seconds. In the early days of the space program, other propellants (or so called metapropellants) were suggested, including atomic hydrogen and liquid ozone. Theoretical and experimental studies of atomic hydrogen and ozone were conducted beginning in the late 1940s. This propellant research may have provided screenwriters with the idea of an atomic hydrogen-ozone rocket engine in the 1950 movie, Rocketship X-M. This paper presents analyses showing that an atomic hydrogen-ozone rocket engine could produce a specific impulse over a wide range of specific impulse values reaching as high as 1,600 s. A series of single stage and multistage rocket vehicle analyses were conducted to find the minimum specific impulse needed to conduct high energy round trip lunar missions.

\section{Nomenclature}

$\begin{array}{ll}\text { A } & \text { Fixed mass scaling parameter, } \mathrm{kg} \\ \mathrm{A} 12, \mathrm{~A} 14, \mathrm{~A} 16 & \text { Percent of atomic hydrogen in a solid molecular hydrogen matrix } \\ \mathrm{B} & \text { Propellant dependent mass scaling parameter, kg/ (kg Mp) } \\ \text { CEV } & \text { Crew Exploration Vehicle } \\ \text { EDS } & \text { Earth Departure Stage } \\ \text { EM-1 } & \text { Exploration Mission 1 } \\ \text { ESAS } & \text { Exploration Systems Architecture Study } \\ \text { ETO } & \text { Earth to orbit } \\ \text { GLOW } & \text { Gross Liftoff Weight } \\ \text { H } & \text { Atomic hydrogen } \\ \text { H2 } & \text { Molecular hydrogen }\end{array}$

* Leader of Advanced Fuels, AIAA Associate Fellow

** $\quad$ AIAA Fellow, Manager, Advanced Space Propulsion, NASA HQ, Retired. 


\begin{tabular}{ll} 
HEDM & High-Energy Density Materials \\
Isp & Specific impulse (seconds) \\
LH2 & Liquid Hydrogen \\
LO2 & Liquid Oxygen \\
Mp & Propellant mass \\
NACA & National Advisory Committee for Aeronautics (predecessor to NASA) \\
NERVA & Nuclear Engine for Rocket Vehicle Applications \\
NTP & Nuclear Thermal Propulsion \\
NTR & Nuclear Thermal Rocket \\
O/F & Oxidizer-to-Fuel ratio \\
O2 & Oxygen \\
O3 & Ozone \\
PBR & Particle Bed Reactor \\
RX-M & Rocketship eXpedition - Moon \\
SEI & Space Exploration Initiative \\
SF & Science fiction \\
T/W & Thrust to Weight ratio \\
Wt $\%$ & Weight percent \\
\hline
\end{tabular}

\section{Introduction}

High energy propellants for human lunar missions are analyzed, focusing on very advanced ozone and atomic hydrogen. One of the most advanced launch vehicle propulsion systems, such as the Space Shuttle Main Engine (SSME), used hydrogen and oxygen and had a delivered specific impulse of 453 seconds. In the early days of the space program, other propellants (or so called meta-propellants) were suggested, such as many combinations including atomic hydrogen or liquid ozone, or both. Theoretical and experimental studies of atomic hydrogen and ozone were conducted beginning in the late 1940s. An atomic hydrogen-ozone mixture provides the desired attributes of high combustion temperature and low reactant mass. This research may have provided screenwriters with the idea of an atomic hydrogen-ozone rocket engine in the 1950 science fiction (SF) movie, Rocketship X-M (Ref. 1). This paper presents the results of a study which shows that theoretically an atomic hydrogen-ozone rocket engine could produce a specific impulse approaching 1,600 s. The feasibility of such a propulsion system will be discussed.

\section{Advanced Propellants}

Advanced propellant and propulsion systems analyses were conducted for very high delta-V lunar missions. The vehicle analyses used the performance assumptions of atomic hydrogen and ozone as the propellants. In the mission design, the delta- $\mathrm{V}$ for each maneuver was the worst case (highest) value for Earth escape velocity and lunar escape velocity. In other words, the total delta- $\mathrm{V}$ was computed assuming that the vehicle left the surface of the Earth, attained Earth escape velocity, arrived at the Moon, and landed with a vertical touchdown. To return to Earth, the vehicle once again delivered the delta- $\mathrm{V}$ for lunar escape velocity, and landed on the Earth, delivering the retro-propulsion delta- $\mathrm{V}$ equivalent to Earth escape velocity. Additional mission analyses were conducted assuming that an aerodynamic descent to Earth was used. The SF inspired vehicle is a two stage design, with Stage 1 being left behind on the Moon. The vehicle design was based in part on the implications of the SF film Rocketship X-M (Ref. 1). 


\section{Lunar Mission Planning and Mission delta-V}

Based on the past historical data and information that can be inferred from the $1950 \mathrm{SF}$ film, the mission delta- $\mathrm{V}$ budget was developed. Its mission was to send a crew to the moon and return. The vehicle in the SF film used a two stage design. The initial thrust level of the SF inspired rocket was 2,300 MT (Ref. 1).

There are two basic mission scenarios that were used. The first was a round trip mission to the Moon based on a brute force approach. There were four delta-V maneuvers: liftoff from Earth onto an escape trajectory toward the Moon, a soft landing on the Moon, ascent from the Moon onto an escape trajectory toward Earth, and finally an all propulsive landing on Earth. The delta- $\mathrm{V}$ values in the table include a $20 \%$ gravity loss for each maneuver. The delta- $\mathrm{V}$ values are noted in Table I. The total mission delta- $\mathrm{V}$ was $32.83 \mathrm{~km} / \mathrm{s}$.

The second mission scenario has the same maneuvers but does not use the all propulsive landing on Earth. Upon entering the Earth's atmosphere, the vehicle would glide to a landing. The total delta- $\mathrm{V}$ for this scenario is $19.41 \mathrm{~km} / \mathrm{s}$.

\begin{tabular}{lcc}
\multicolumn{3}{c}{ Table I. Mission delta-V values $(\mathrm{km} / \mathbf{s})$} \\
Maneuver & Gliding return & All Propulsive \\
\hline Earth departure & 13.4 & 13.4 \\
Moon arrival and landing & 3.0 & 3.0 \\
Moon departure & 3.0 & 3.0 \\
Earth arrival & 0.0 & 13.4
\end{tabular}

\section{A. Vehicle Design Options and Staging}

In conducting the high energy mission mass estimates, it became clear that the number of stages should be investigated. For extremely high delta-V missions, there is a strong benefit in using multiple stages; a multistage vehicle is less massive. A less massive vehicle often reduces the cost of mission facilities and allows a reduction in mission complexity. In the SF film, the vehicle was to have two stages. Several options were investigated: 1 stage, 2 stages, and 6 stages for the very advanced propellants.

As the vehicle Isp required to perform the 2 stage missions was quite high, a 6 stage lunar vehicle was also analyzed. Such an option very often reduced the overall vehicle GLOW, and also reduced the Isp needed for a very high energy mission. Finally, a single stage vehicle mass was estimated. While the single stage vehicle will require a very high Isp value, the design case was included for comparison.

Other options considered were related to the planned Nova launch vehicle (Ref. 2). Here, a total of 4 stages were used. Two stages were used for Earth departure, and one each stage for lunar landing, lunar ascent. The vehicle returns the crew capsule to Earth via a parachute landing. Additionally, the liftoff mass needed for the typical lunar missions planned under the Space Exploration Initiative using STS-C launch vehicles (SEI, from 1980's and 1990's) is also presented (Ref. 3).

\section{B. Propulsion Mass Estimation}

Mass scaling equations were used for the dry mass estimation.

The mass scaling equation was based on historical methods of propulsion sizing (Refs. 3 and 4):

$\operatorname{Mdry}(\mathrm{kg})=\mathrm{A}+\mathrm{B} \mathrm{Mp}$ 
where:

$$
\begin{array}{ll}
\text { Mdry } & =\text { Propulsion system dry mass including residual propellant }(\mathrm{kg}) \\
\mathrm{Mp} & =\text { Usable propellant mass }(\mathrm{kg}) \\
\mathrm{A} & =\text { fixed propulsion system mass }(\mathrm{kg}) \\
\mathrm{B} & =\text { propellant mass dependent mass }(\mathrm{kg} / \mathrm{kg} \mathrm{Mp})
\end{array}
$$

\begin{tabular}{lcc}
\multicolumn{2}{c}{ Table II. Propulsion mass scaling parameters } \\
Vehicle type & Isp (s) & $\mathrm{B}(\mathrm{kg} / \mathrm{kg} \mathrm{Mp})$ \\
\hline Advanced & Appendix A & $0.15,0.20$ \\
STS-C & - & - \\
Nova class & 410,450 & $0.10,0.15$
\end{tabular}

For the advanced propellants, the B parameter was either 0.15 or 0.20 . These values are reasonable for advanced chemical propulsion (Ref. 4). With the SEI based STS-C cases, no additional analyses were conducted, and the GLOW of the launch vehicle was taken from the literature (Ref. 5). For the Nova class vehicle, the B parameter was selected based on historical oxygen /hydrogen propulsion system sizing (Refs. 3 and 4). The crew accommodations or the vehicle payload mass of 13.6 MT was selected based on past studies (Ref. 6).

\section{Propulsion and Propellant Analyses}

The Isp performance of a wide range of advanced propellant options were estimated. Figures 1 (Ref. 7) and 2 depict the Isp versus mixture ratio of oxygen and atomic hydrogen (H2) and ozone and atomic hydrogen, respectively. In the atomic propellant analyses, several high-energy density atomic propellants with solid particle feed systems were considered (Ref. 7). Analyses of atomic aluminum (Al), atomic boron (B), atomic carbon (C), and atomic hydrogen $(\mathrm{H})$ were conducted. In the analyses, the atomic additives were stored in solid cryogenic $\mathrm{H} 2$ particles with a cryogenic helium liquid as the carrier fluid. Atomic hydrogen had the highest theoretical performance. As shown in Figure 1, the specific impulse of atomic hydrogen could reach 1,600 s for 100 weight\% $\mathrm{H}$ (Ref. 7). The analysis includes some bipropellant cases with $\mathrm{O} 2$ as the oxidizer. The best performance was with the monopropellant, $\mathrm{H}$. The energy for the high specific impulse of an atomic hydrogen engine comes from the recombination of the hydrogen atoms. The analyses were performed with the CEA (Chemical Equilibrium with Applications) computer code. Refs. 8 and 9).

Figure 1 presents the specific impulse (Isp) performance for atomic hydrogen with oxygen as the oxidizer (Ref. 7). Figure 2 depicts the Isp performance for atomic hydrogen with ozone (O3) as the oxidizer. In most cases, the engine Isp values were compatible with the very high mission delta- $\mathrm{V}$ that is needed. Appendix A provides a wide range of Isp performance analyses for a wide variety of advanced propellant combinations. Appendix B discusses the history of some of these propellants. 


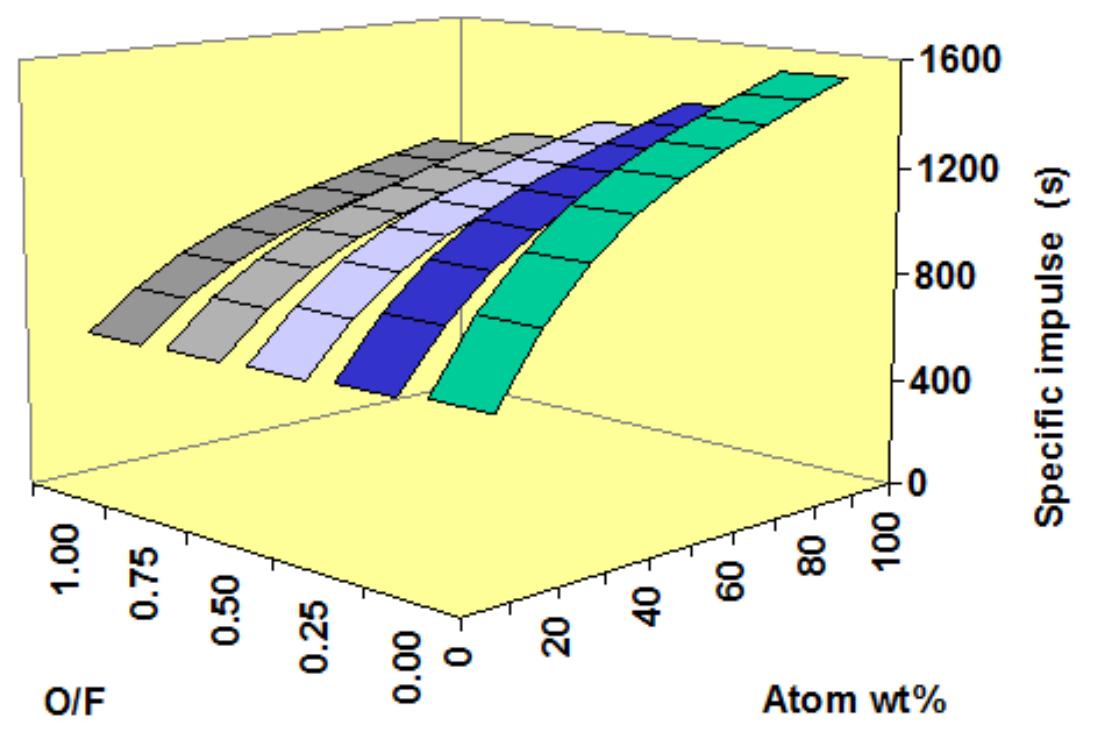

Figure 1. Atomic hydrogen engine performance, no helium diluent added (Palaszewski, B., "Launch Vehicle Performance With Solid Particle Feed Systems for Atomic Propellants,” NASA / TM-1998-208498 AIAA-98-3736)

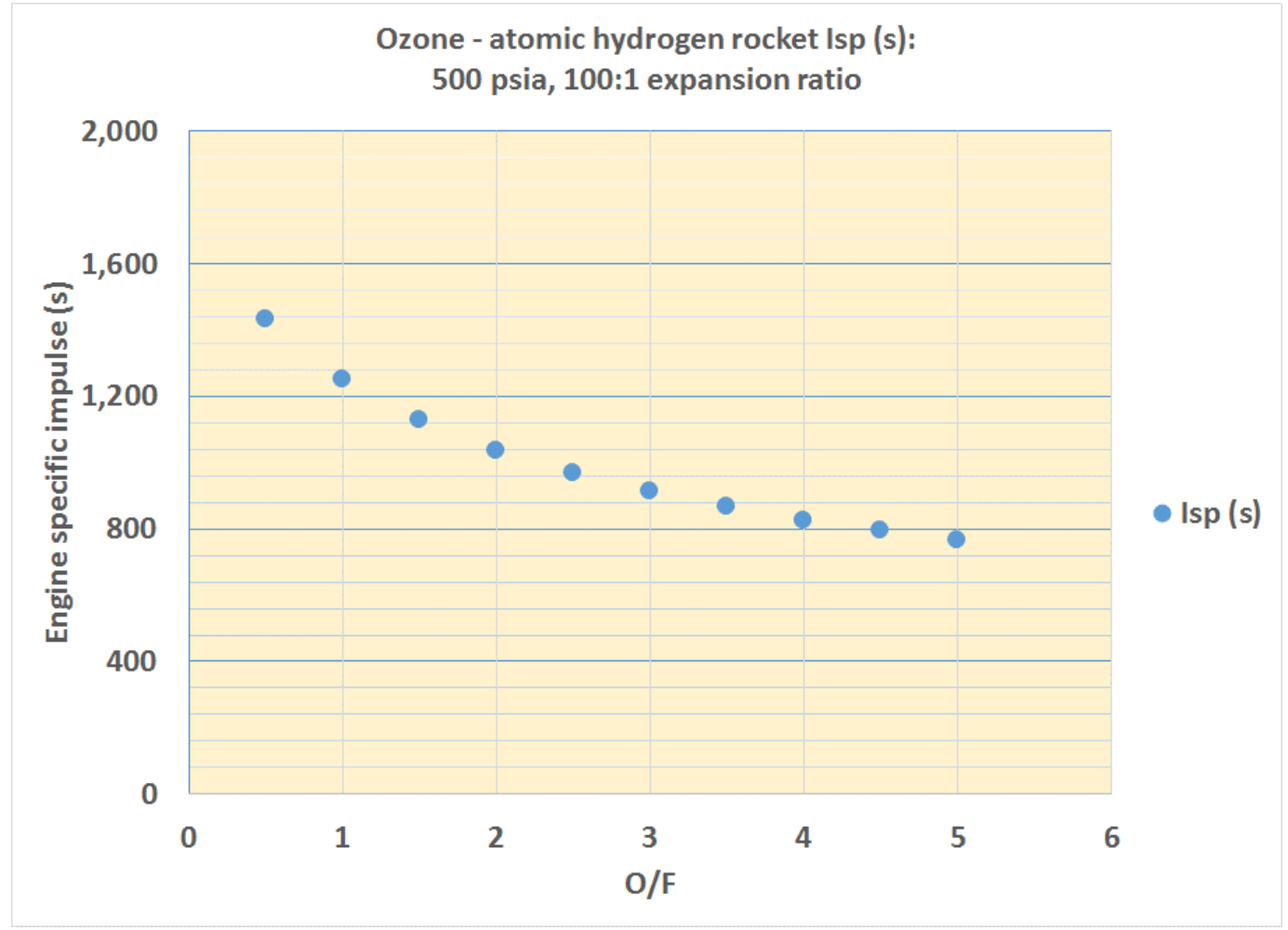

Figure 2. Ozone and atomic hydrogen engine performance, 100:1 expansion ratio, no helium diluent added 


\section{A. GLOW Estimates and Point Design Results}

Based on the information in the SF film, the liftoff thrust of the lunar vehicle was 2,300 MT. Using a thrust to weight (T/W) ratio of 1.2, the maximum liftoff mass of the vehicle should be approximately 1,900 MT. This T/W ratio is representative of historical launch vehicles.

Initial mass estimates of the lunar vehicles began with the using typical advanced propellant Isp values. The initial cases are shown in Figure 3. Five cases are presented: 2 with the gliding return to Earth and 3 with the all-propulsive lunar mission. A set of Isp combinations for a 2 stage lunar vehicle were tested. For the gliding return to Earth, the two cases differ in the Isp of the second stage: 1,100 and 1,500 seconds. Stage 1 used a 522 second Isp value. The all-propulsive mission design was used in three Isp combinations: 1,500 s (Stage 2) and $900 \mathrm{~s}$ (Stage 1), 1,500 s (Stage 2) and 1,050 s (Stage 1), and $1,100 \mathrm{~s}$ in both stages. The option using 1500 seconds in stage 2 and 1050 seconds in stage 1 allowed a sufficiently low GLOW to fit into the SF space vehicle GLOW limit of 1900 MT. Again, these three Isp combination were used to guide the vehicle design and find a "best" option for each stage's Isp value.

These initial GLOW estimates were used to establish more complete GLOW versus Isp maps for each vehicle design. Initially, the 2 stage vehicle was thought to be sufficient in meeting the allpropulsive mission design. However, the Isp needed to fit within the GLOW limit was still quite high. Variations in the B parameter of the mass scaling equation and the number of stages were investigated to find an improved design with the lowest possible Isp value.

\section{GLOW Comparison - RX-M, Ozone and Atomic Hydrogen}

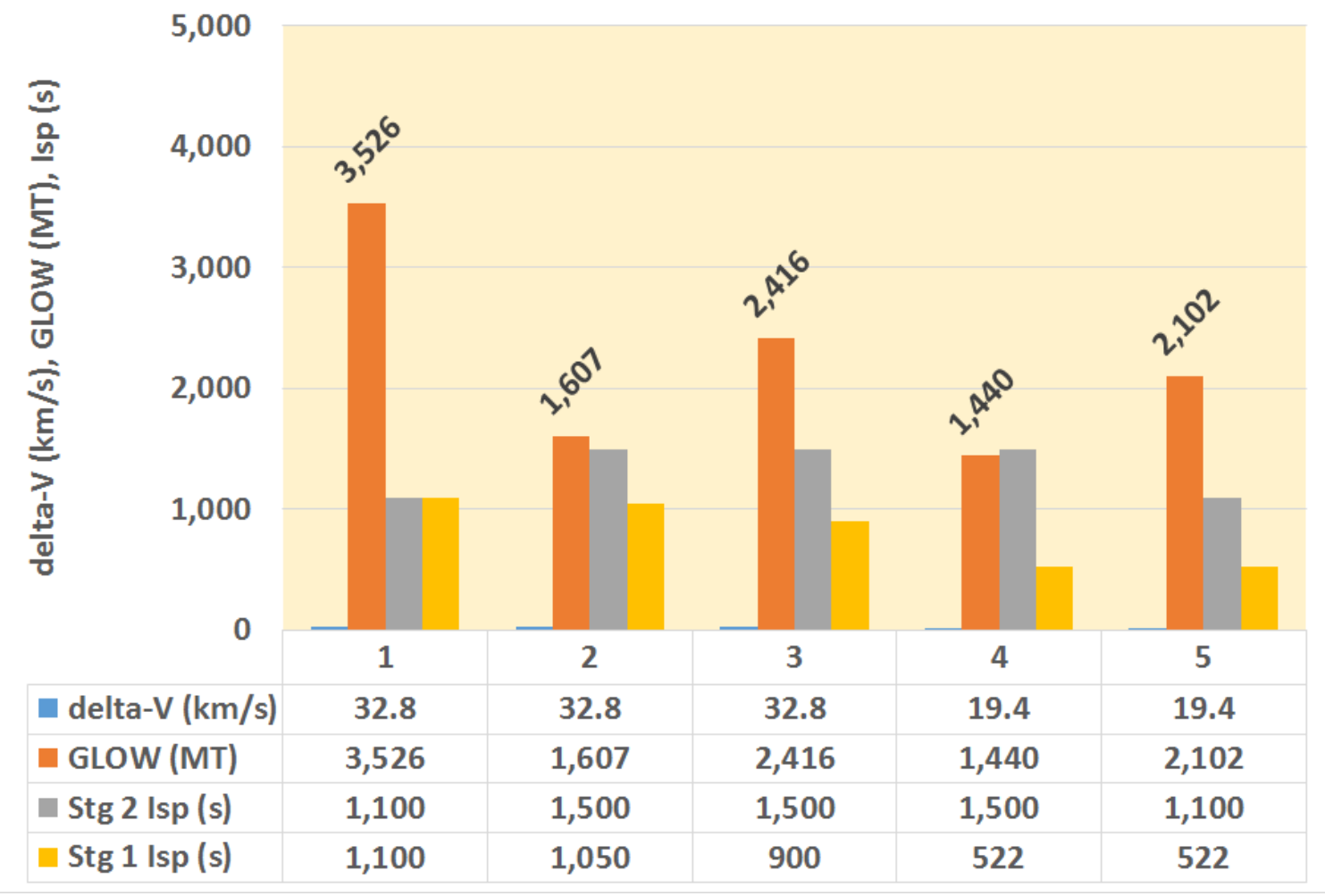

Figure 3. Initial point design analyses for advanced propellants with the high energy lunar missions 


\section{B. Parametric GLOW Results}

Multiple options for the advanced propellants allowed the mission designer to find the minimum Isp value needed to complete the mission. Figure 4 compares the GLOW for 2 cases: in the first case, the Isp of stage 2 is $1500 \mathrm{~s}$ and stage 1 Isp varies. In the second case, the Isp of each stage is the same. The range of Isp investigated was 1,100 to $1,500 \mathrm{~s}$.

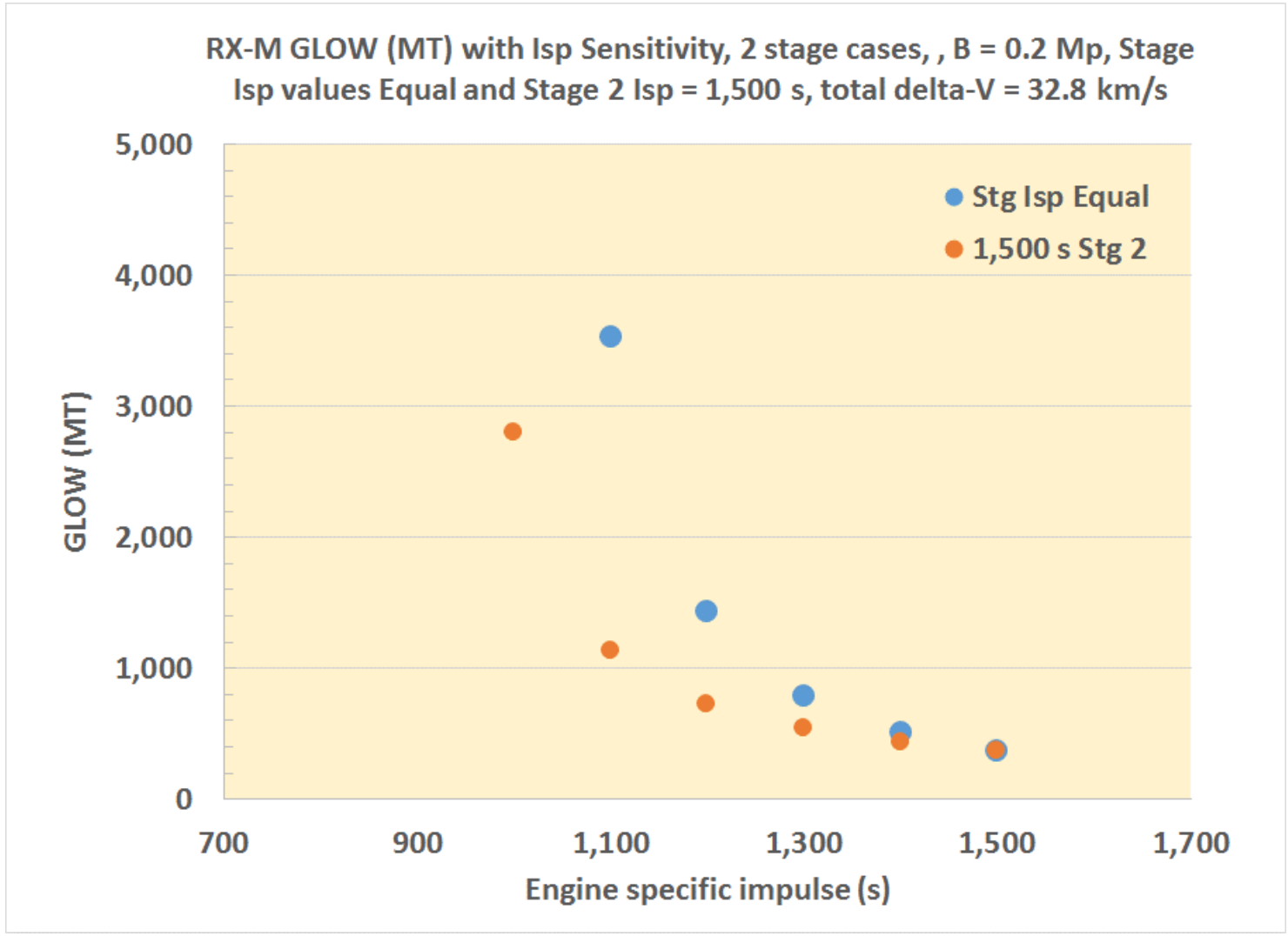

Figure 4. GLOW and Isp sensitivity, same dry mass fraction for each stage $(B=0.20$ for both Stages 1 and 2).

Figure 4 provides a comparison of the GLOW versus Isp for two cases. The cases are where the 2 stages have the same Isp. The other case is where the first stage Isp varies, but the $2^{\text {nd }}$ stage Isp is fixed at $1500 \mathrm{~s}$. For the GLOW limit of 1900 MT, the vehicle Isp of approximately 1,150 (Stage Isp Equal) and 1,050 seconds (1,500 s Stage 2), respectively. In each case, the B parameter is 0.2 . The Isp value that corresponds to the 1,900 MT GLOW is $1,160 \mathrm{~s}$ for the case with the stage Isp values being equal; for the $1500 \mathrm{~s}$ stage 2, the Isp value for the 1,900 MT GLOW was 1,030 s.

In Figure 5, the influence of the stage dry mass is presented. There are 2 cases: $B=0.15$ in Stage 1 and $\mathrm{B}=0.20$ in Stage 1. The Isp of Stage 2 is $1,500 \mathrm{~s}$. By reducing the stage dry mass, the overall GLOW of the vehicle can be reduced. Alternatively, if the GLOW were to remain constant (near the T/W based limit of approximately 1,900 MT), the Isp of Stage 1 can be reduced to approximately $920 \mathrm{~s}$. A 
lower Isp stage can allow the use of a less energetic propellant combination that will be less difficult to produce.

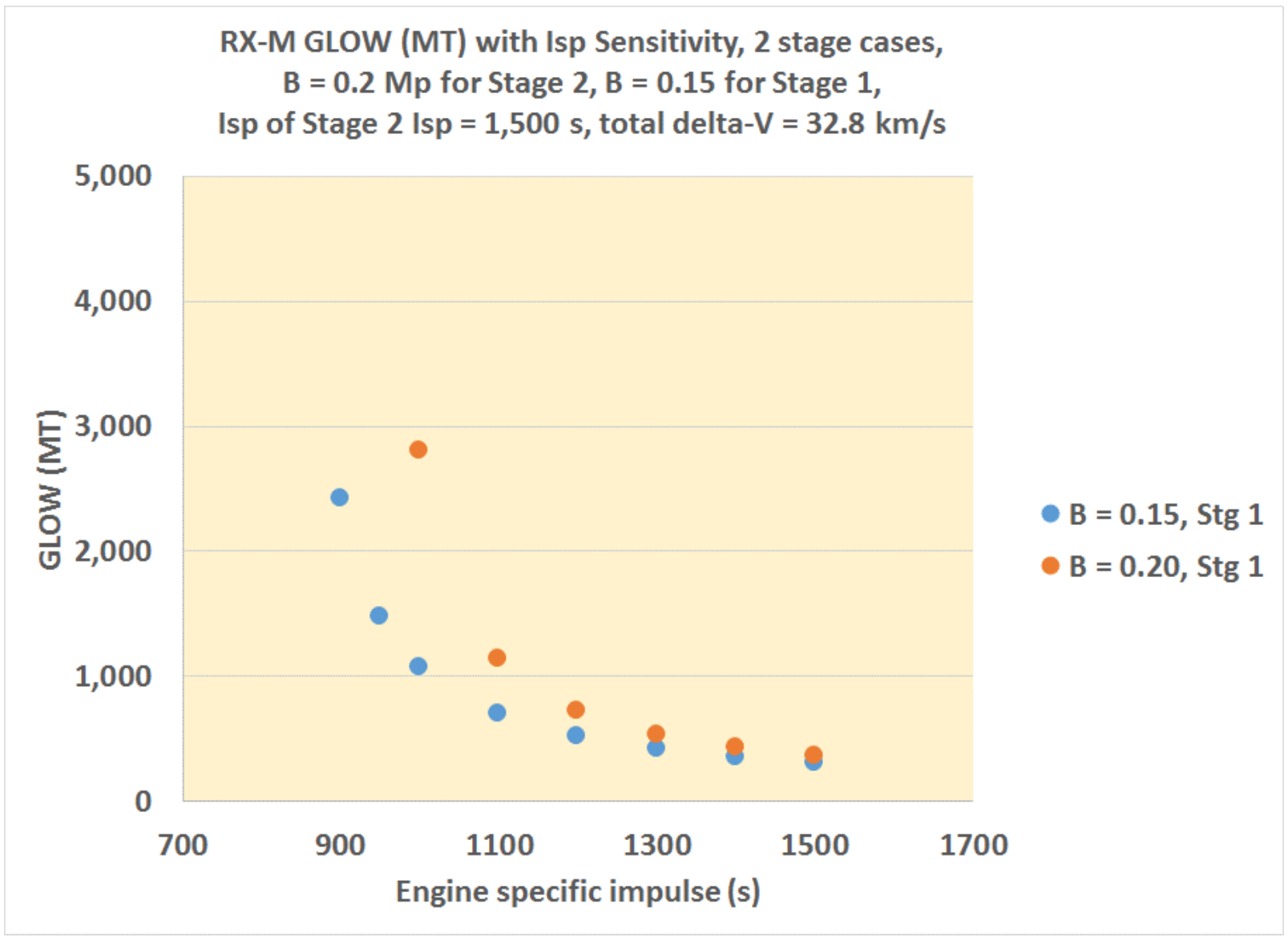

Figure 5. GLOW and Isp sensitivity, different dry mass fraction for each stage $(0.20$ for Stage 2 and 0.15 for Stage 1)

For extremely high delta-V missions, often many stages reduces the overall mass of the vehicle, or for a fixed GLOW, a minimum Isp can be found. In an effort to find the lowest possible Isp for the advanced propellant combination with partial reusability, a simulation was conducted for a 6 stage lunar mission. Two stages were used for the Earth departure; one was used for the lunar landing and one for the lunar ascent. The final 2 stages are used for an all propulsive Earth landing. Only the final $6^{\text {th }}$ stage and the human capsule system lands in the all-propulsive mode upon return to Earth. In this set of analyses, the Isp was the same for every stage 


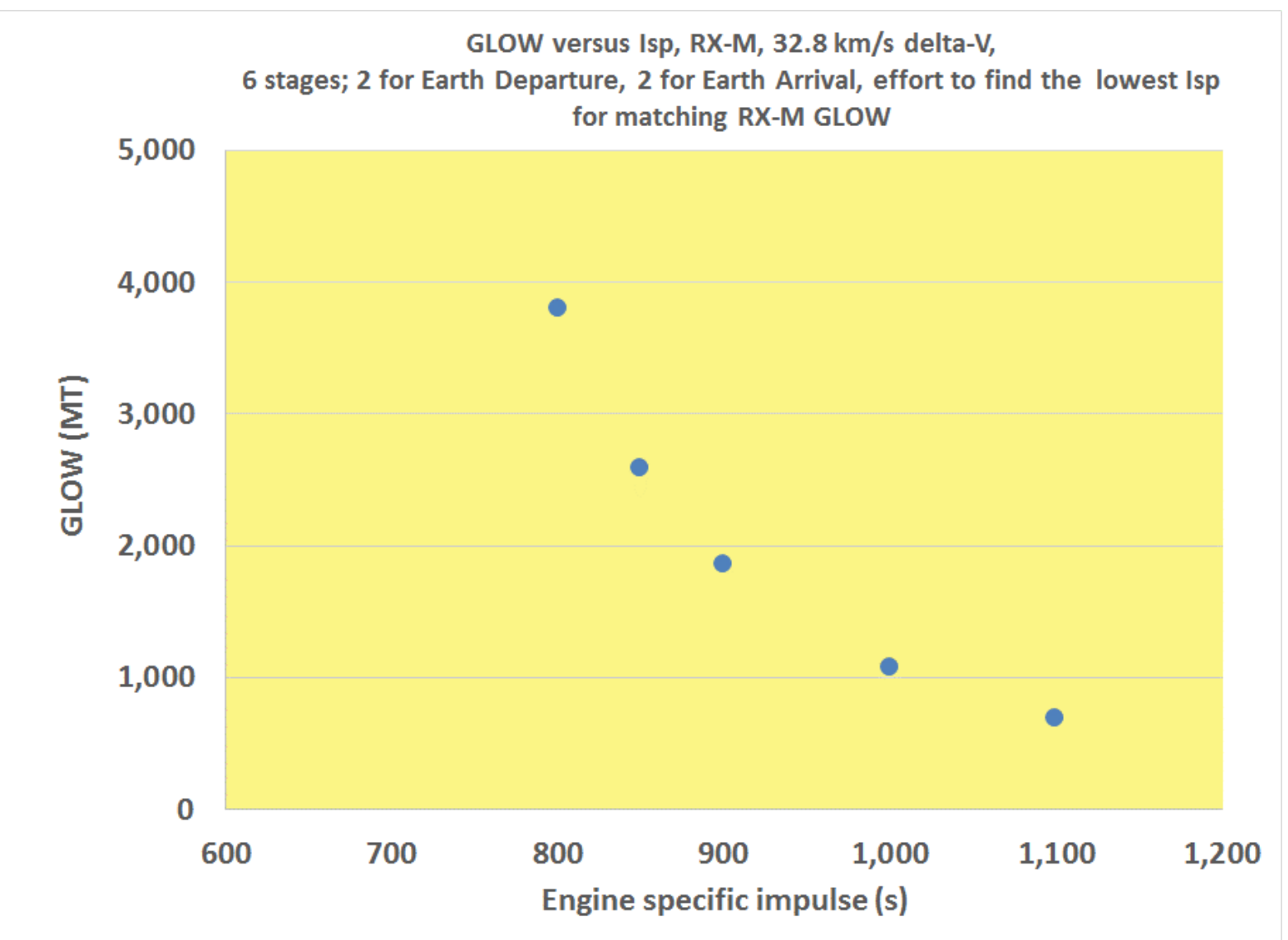

Figure 6. GLOW and Isp sensitivity, 6 stage vehicle for lunar mission $(\mathrm{B}=0.20$ for all stages).

The 6 stage option results are shown in Figure 6. In the high energy propellant cases, the GLOW of the vehicle was limited to approximately 1,900 MT. In this configuration with the GLOW of 1,900 MT (based on the T/W limit) for the lunar vehicle, the lowest Isp that can allow this mission is approximately 900 seconds. This lower Isp is less challenging than the 1,500 second value noted for many of the other cases that were presented. However, the 900 second Isp value is still far above the traditional 450 to 470 second Isp values noted for the currently available O2/H2 propulsion systems.

For comparison, the GLOW of a single stage vehicle was also assessed. The 1 stage vehicle GLOW is depicted in Figure 7. To fit within the limit of approximately 1,900 MT, the rocket engine Isp value must be approximately 1,680 s. This Isp value is beyond the predicted capability of the advanced propellant combinations discussed in this set of propellant analyses. This result clearly shows the importance of multistage space vehicle design.

\section{Nova Class Vehicles:}

For comparison, a 4 stage lunar mission using chemical $\mathrm{O} 2 / \mathrm{H} 2$ propulsion was considered in the comparison. The 4 stage vehicle was used as it was a suggestion in the early Apollo mission planning for a brute force lunar mission scenario, using a Nova class rocket. The 4 stage vehicle used 2 stages to inject the payload onto an escape trajectory. The $3^{\text {rd }}$ stage would softly land the vehicle on the Moon. 
The $4^{\text {th }}$ stage would place the crew capsule onto a lunar escape trajectory toward Earth; the crew capsule would land via parachute.

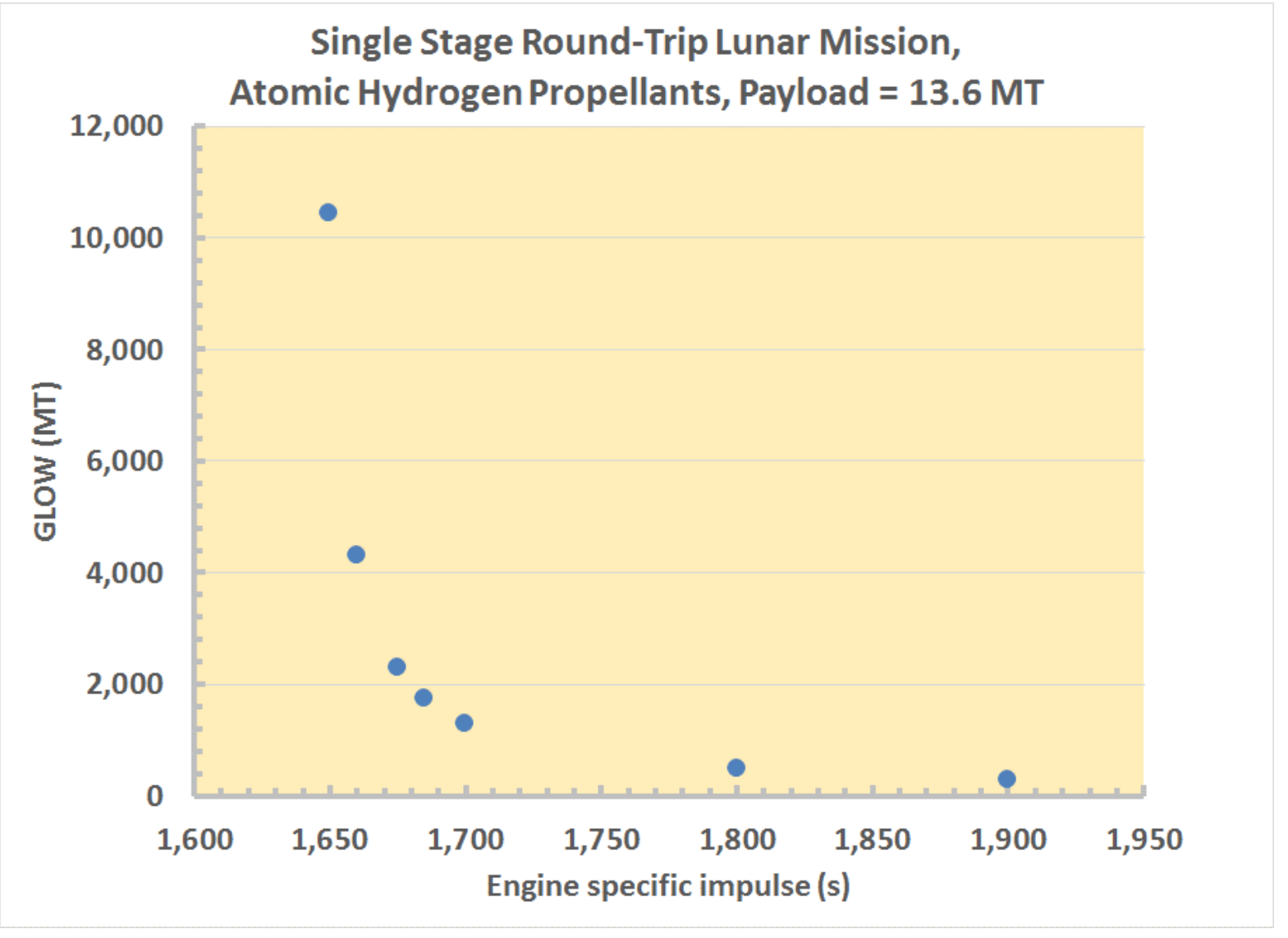

Figure 7. GLOW and Isp sensitivity, 1 stage vehicle for lunar mission (B $=0.20$ for all stages).

Additional analyses were conducted to compare the RX-M vehicle with a planned lunar mission based on the Nova class vehicle concept of the 1960's. With the Nova class rocket, the lunar mission would lift off from Earth, fly directly to the lunar surface, land softly, and then with a final rocket propulsion system, fly directly back to Earth with crew recovery being enabled with a three person capsule. This analyses used a 4 stage vehicle: 2 stages for the earth departure, 1 for the lunar descent, and one for the lunar ascent and return to Earth. Based on historical analyses of Nova, either a $410 \mathrm{~s}$ or a $450 \mathrm{~s}$ Isp was planned. Figure 8 shows the GLOW for 4 cases: 2 with an Isp of $410 \mathrm{~s}$ and 2 with an Isp of $450 \mathrm{~s}$. For each Isp value, as different stage dry mass parameter, B, was used. For the 450 second Isp cases, the GLOW was 5,040 MT to nearly 7,000 MT.

\section{STS-C GLOW for NASA Lunar Missions}

Figure 9 provides the number of STS-Cargo (STS-C) launch vehicles required for the human lunar missions planned for the Space Exploration Initiative (SEI). The GLOW for a single STS-C was planned to be 2,000 MT (Ref. xx). Thus, the minimum GLOW required for the lunar missions was 8,000 MT (for 4 launches). 


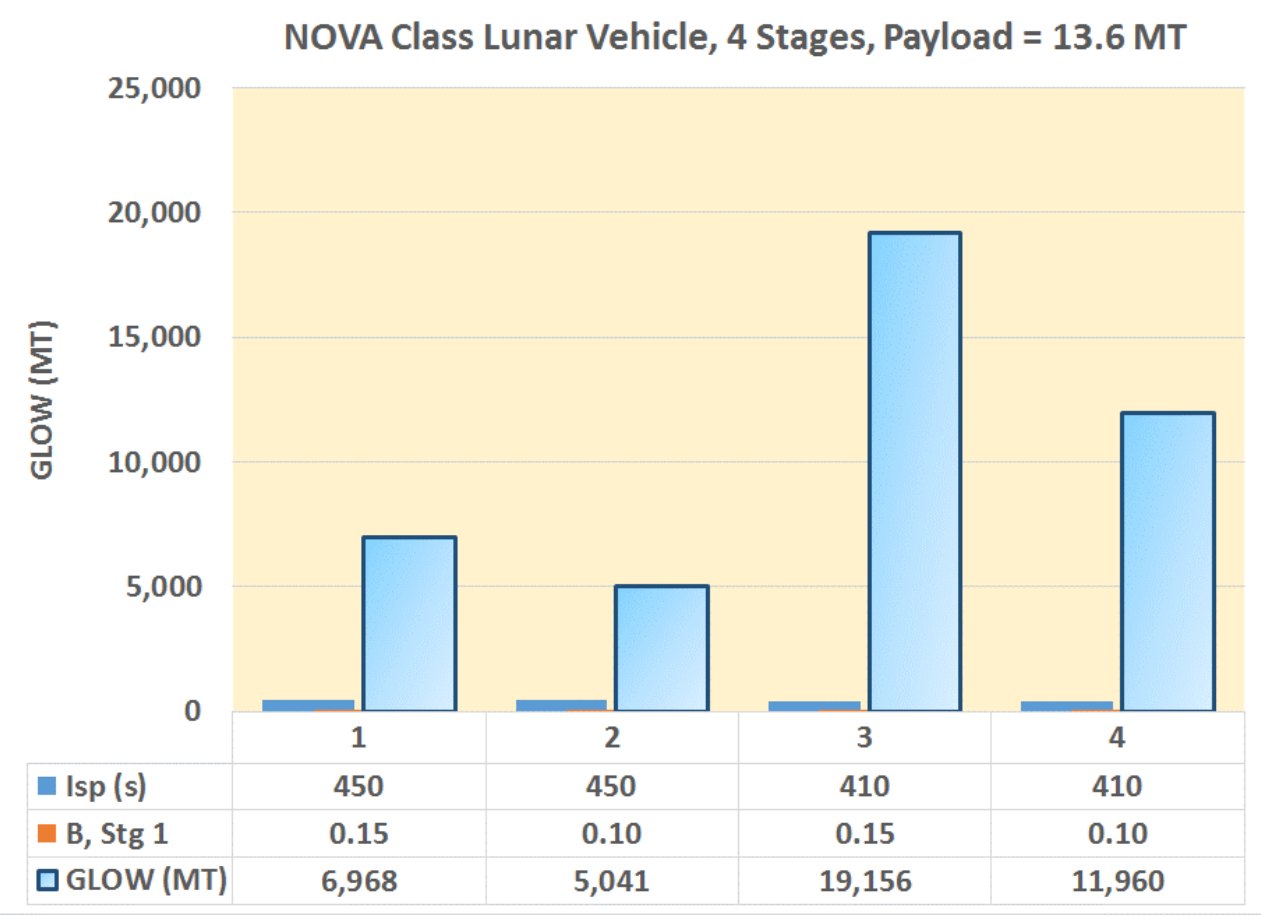

Figure 8. GLOW and Isp sensitivity, 4 stage Nova class vehicle for lunar mission ( $B=0.15$ or 0.10 for stage 1 ).

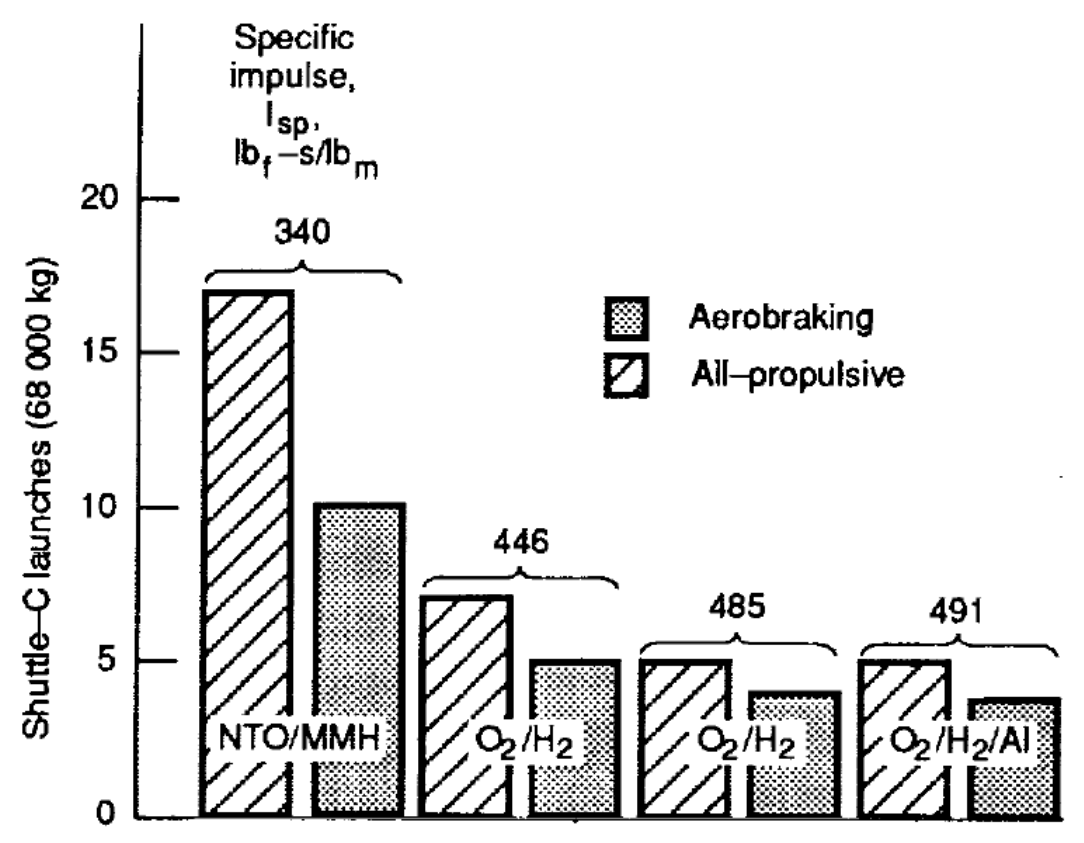

Figure 9. Number of STS-C launches for lunar mission (Ref. 3). 
Figure 10 compared the advanced propellants, Nova and SEI (STS-C based) space vehicle GLOW values. The three advanced propellant cases show the lowest Isp value for the mission. The lowest Isp for the advanced propellants was $900 \mathrm{~s}$; here, the vehicle had six stages. An ozone / atomic hydrogen propellant combination or an atomic hydrogen propellant alone may accomplish the allpropulsive mission design. The second lowest Isp value was $1,160 \mathrm{~s}$, and this Isp was for the 2 stage vehicle, again with the all-propulsive mission design. Lastly, the single stage vehicle required an Isp value of 1,680 s; based on the analyses presented here, none of the advanced propellants that were presented can enable this mission design. The Nova class vehicle with an Isp value of $450 \mathrm{~s}$ can perform the round trip lunar mission, but not in the all-propulsive mode. The final stage, once it departs and escapes from the lunar gravity, will return to Earth via high energy reentry and finally using a parachute. Though the SEI vehicle using four STS-C launches has a different payload delivery mission, and was composed on many lunar vehicle components that required on-orbit assembly in LEO, it was presented for comparative purposes.

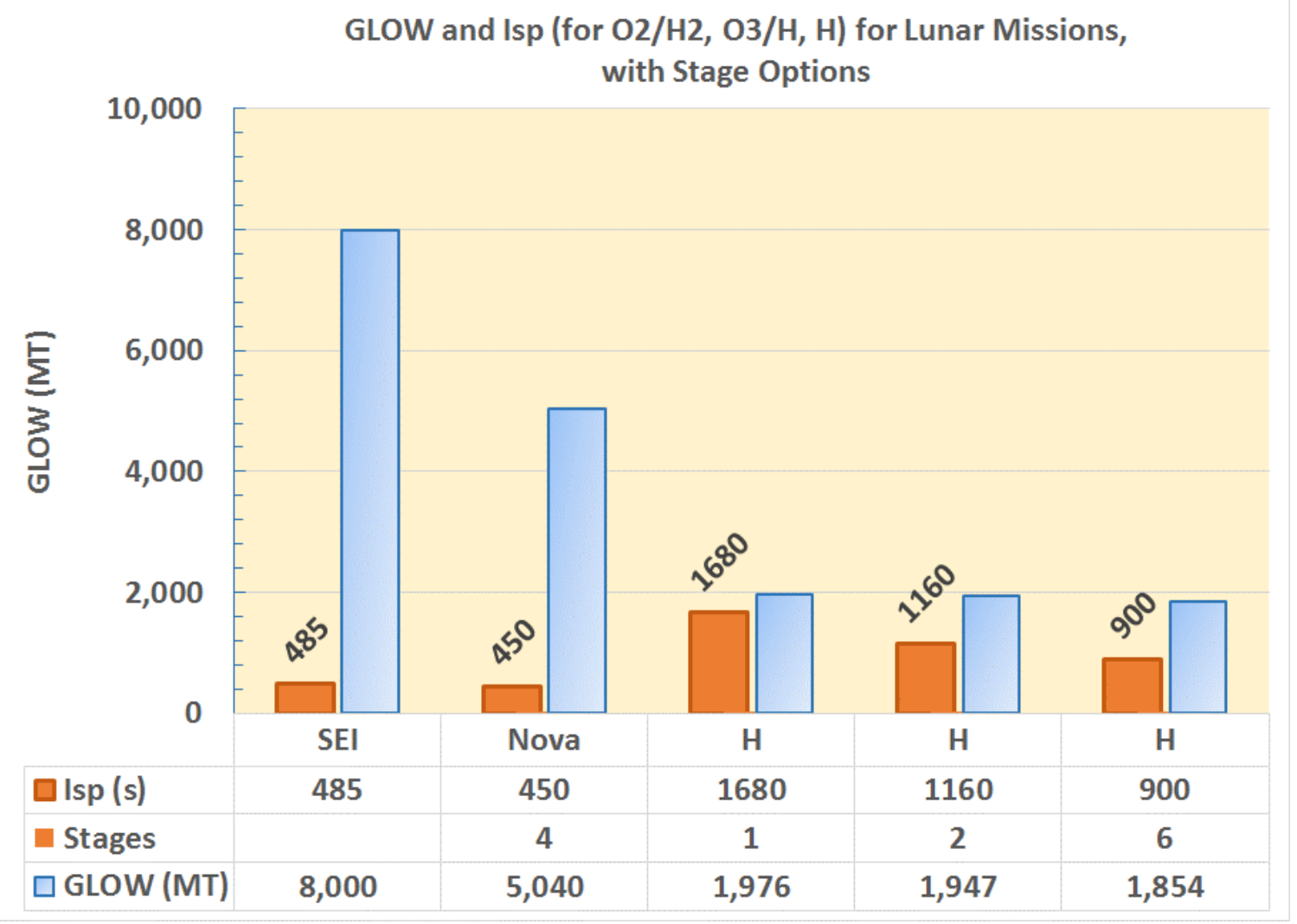

Figure 10. GLOW and Isp sensitivity, two chemical propellant combinations using $\mathrm{O} 2 / \mathrm{H} 2$ and three advanced propellant vehicle for lunar mission (with $\mathrm{B}=0.20$ for all advanced propellant stages).

\section{Concluding Remarks}

The GLOW estimates for a variety of lunar missions with advanced chemical propulsion were calculated. With traditional O2/H2 propulsion, the SEI cases showed a GLOW of 8,000 MT using 4 STS-C launch vehicles. This GLOW is exceptionally high, and is driven by the limits of the launch vehicle, the large payload delivered to the lunar surface (27 MT, delivered robotically), and many components that were delivered to LEO and assembled there for the lunar round trip. All of the other 
cases used a fixed mass that supported a crew and completed a lunar round trip mission. The Nova class cases used a simplified mission scenario, carrying the crew module to the Moon and them returning it bay parachute to Earth. The advanced high energy fuel cases were designed to use 1, 2 or 6 stages. These analyses showed the potential of using staging to reduce the maximum Isp needed to complete the missions. A 900 second Isp was needed for the 6 stage case. An Isp value of nearly 1,700 seconds was needed for the 1 stage case.

The GLOW of a series of lunar missions was estimated. The high energy propulsion vehicles were limited to a GLOW of 1,900 MT (based on a T/W of 1.2). In the comparisons, the lowest Isp to meet that GLOW limit was calculated. For the 1 stage lunar vehicle, the minimum Isp to meet the GLOW requirement was about $1680 \mathrm{~s}$. With the 2 stage vehicle, the minimum Isp was approximately $1,160 \mathrm{~s}$. Using the 6 stage vehicle, the minimum Isp was $900 \mathrm{~s}$. In comparison, for traditional chemical $\mathrm{O} 2 / \mathrm{H} 2$ propulsion, the configuration of a 4 stage Nova class vehicle required 5,040 MT.

Overall mission planning should include variations of the number of stages and a variety of propulsion technologies. In the past SF films. The rocket vehicle performance was often misquoted or misused as a toll of the screenplay. In most SF films, the producers never get all of the numbers right. However, SF films offer inspiration for new discoveries as humanity makes its way the planets and to the stars.

\section{References}

1) Lippert Pictures, “Rocketship X-M,” (film, Hollywood, USA, production), 1950.

2) Huber, N. G. "Post-Saturn launch vehicle study, Part II, Condensed Summary Report," NASA Marshall Space Flight Center, NASA-TM-X-53010, Apr 10, 1964.

3) Palaszewski, Bryan, "Lunar Missions Using Chemical Propulsion: System Design Issues", NASA Technical Paper 3065, prepared for the AIAA/ASME/SAE/ASEE 26th Joint Propulsion Conference, Orlando, Florida, 16-18 July 1990.

4) Palaszewski, B., "Launch Vehicle Performance with Solid Particle Feed Systems for Atomic Propellants," NASA /TM-1998-208498 AIAA-98-3736.

5) "HLLV Options For The Space Exploration Initiative, Definition of a Space Transportation Systems Cargo Element (Shuttle-C),” NAS8-37143, DR-8, PRELIMINARY DESIGN DOCUMENT, September 1990.

6) Mark G. Benton, et al., "Modular Space Vehicle Architecture for Human Exploration of Mars using Artificial Gravity and Mini-Magnetosphere Crew Radiation Shield.” AIAA 2012-0633. 2012.

7) Palaszewski, B., "Launch Vehicle Performance With Solid Particle Feed Systems for Atomic Propellants," NASA / TM-1998-208498 AIAA-98-3736.

8) Gordon, Sanford and McBride, Bonnie J., Computer Program for Calculation of Complex Chemical Equilibrium Compositions and Applications, I. Analysis, NASA Reference Publication 1311, October 1994.

9) McBride, Bonnie J. and Gordon, Sanford, Computer Program for Calculation of Complex Chemical Equilibrium Compositions and Applications, II. User's Manual and Program Description, NASA Reference Publication 1311, June 1996. 


\section{Bibliography}

1 Dale, Shana, "Exploration Strategy and Architecture", 2nd Space Exploration Conference: Implementing the Vision, AIAA, 4-6 December 2006, George R. Brown Convention Center, Houston TX.

2 NASA, NASA’s Exploration Systems Architecture Study Final Report, NASA-TM-2005-214062, November 2005.

3 Miller, Charles, et al., Economic Assessment and Systems Analysis of an Evolvable Lunar Architecture that Leverages Commercial Space Capabilities and Public-Private-Partnerships, NexGen Space LLC, 13 July 2015.

4 Borowski, Stanley K., Corban, Robert R., McGuire, Melissa L., and Beke, Erik G., "Nuclear Thermal Rocket/Vehicle Design Options for Future NASA Missions to the Moon and Mars", AIAA-93-4170, Space Programs and Technologies Conference and Exhibit, AIAA, Huntsville, Alabama, 21-23 September 1993 (also NASA Technical Memorandum 107071).

5 Borowski, S. K., Lapointe, M. R., Houts, M. G., and Warren, J. W., "Nuclear Thermal Rocket (NTR) Propulsion: 'Before The Decade Is Out'”, paper 3088, Nuclear and Emerging Technologies for Space (2012), held at The Woodlands, Texas, 21-23 March 2012.

6 Blevins, John A., Patton, Bruce, Rhys, Noah O., and Schmidt, George R., "Limitations of Nuclear Propulsion for Earth to Orbit", AIAA 2001-3515, prepared for the 37th AIAA/ASME/SAE/ASEE Joint Propulsion Conference, Salt Lake City, Utah, 8-11 July 2001.

7 “Saturn V”, Wikipedia, (https://en.wikipedia.org/wiki/Saturn_V), accessed 22 March 2016.

8 "Space Launch System", NASA Facts, George C. Marshall Space Flight Center, Huntsville, Alabama, FS-2016-02-04-MSFC.

9 "Tsiolkovsky rocket equation", Wikipedia, https://en.wikipedia.org/wiki/Tsiolkovsky_rocket_equation), accessed 27 February 2016.

10 Goddard, Robert H., "A Method of Reaching Extreme Altitudes” Smithsonian Miscellaneous Collections, Vol. 71, No. 2, Publication 2450, Published 1919.

11 Oberth, Hermann, Die Rakete zu den Planetenräumen (The Rocket into Interplanetary Space)

12 Zwicky, Fritz, "Fundamentals of Propulsive Power" presented at the International Congress for Applied Mechanics, Paris, 22-29 September 1946.

13 Zwicky, Fritz, "Propellants for Tomorrow's Rockets" in Propulsion Techniques, Action and Reaction, P. J. Turchi, Ed., AIAA, Reston VA, 1998. Originally published in Astronautics, August 1957 (pp. 46-49, 95).

14 Zwicky, Fritz, "Chemical Kinetics and Jet Propulsion", Chemical and Engineering News, Vol. 28, No. 3, pp. 156-158, 16 January 1950.

15 von Braun, Wernher, Whipple, Fred, Ley, Willy, Conquest of the Moon, Cornelius Ryan (ed.), The Viking Press, NY, 1953. York, 1957.

16 Ley, Willy, Rockets, Missiles, and Space Travel, revised and enlarged edition, The Viking Press, New

17 Miller, Riley O. and Ordin, Paul M., Theoretical Performance of Some Rocket Propellants Containing Hydrogen, Nitrogen, and Oxygen, NACA Research Memorandum No. E8A30, Washington, D.C., 26 May 1948.

18 Layton, J. P., Glassman, I., and Garvin, D., “An Evaluation of Liquid Ozone-Oxygen Mixtures as Rocket Oxidizers" in Liquid Propellants Symposium Proceedings, 27-28 March 1957, Volume 3, Office of the Assistant Secretary of Defense Research and Development, PFL 212/17. 
19 Grey, Jerry, private communication, 24 October 2015.

20 Miller, Riley O. and Brown, Dwight D., Effect of Ozone Addition on Combustion Efficiency of Hydrogen - Liquid-Oxygen Propellant in Small Rockets, NASA Lewis Research Center Memo 5-26-59E, Cleveland Ohio, June 1959.

21 McKinley, Jr., J. D. and Garvin, Dick, “The Reactions of Atomic Hydrogen with Ozone and with Oxygen", Journal of the American Chemical Society, Vol. 77, No. 22, pp. 5802-5805 (1955).

22 Giguère, Paul A. and Chin, David, "Reaction Products of Atomic Hydrogen with Solid Ozone", Journal of Chemical Physics, Vol. 31, pp. 1685-1685 (1959).

23 Nicolet, N., "Aeronomic Reactions of Hydrogen and Ozone”, Mesospheric Models and Related Experiments, Vol. 25 of the series Astrophysics and Space Science Library, pp. 1-55, D. Reidel Publishing Company, G. Fiocco (ed.), pp. 1-51 (1971).

24 Howard, Carleton J. and Finlayson-Pitts, Barbara J., "Yields of HO2 in the reaction of hydrogen atoms with ozone", The Journal of Chemical Physics, Vol. 72, No. 6, pp. 3842-3843 (1980).

25 Rocketship X-M, Wikipedia (https://en.wikipedia.org/wiki/Rocketship_X-M), accessed 01 January 2016.

26 Destination Moon, Wikipedia (https://en.wikipedia.org/wiki/Destination_Moon_(film)), accessed 05 October 2015.

27 Palaszewski, “Atomic Hydrogen Propellants: Historical Perspectives and Future Possibilities”, NASA Technical Memorandum 106053, prepared for the AIAA 31st Aerospace Sciences Meeting and Exhibit, Reno, Nevada, 11-14 January 1993.

28 "Rocket to the Moon", Life magazine, 17 January 1949, pp. 67-73.

29 Miller, Ron, "Three Scifi Pioneers Talk About Making the First Great Space Movie”, posted 22 July 2013 (http://io9.gizmodo.com/three-scifi-pionners-talk-about-making-the-first-great-656049023), accessed 28 March 2016.

30 Palaszewski, Bryan, "Launch Vehicle Performance With Solid Particle Feed Systems for Atomic Propellants", NASA/TM-1998-208498 and AIAA-98-3736, prepared for the 34th Joint Propulsion Conference and Exhibit, Cleveland, Ohio, 13-15 July 1998.

31 Orion (spacecraft) Wikipedia (en.wikipedia.org/wiki/Orion_(spacecraft)), accessed 01 April 2016.

32 Palaszewski, B., " Solid Hydrogen Experiments For Atomic Propellants: Particle Formation, Imaging, Observations, and Analyses," AIAA 2003-4688, presented at the 39th AIAA/ASME/SAE Joint Propulsion Conference, Huntsville, AL, July 2003.

34 Palaszewski, B., " Solid Hydrogen Experiments For Atomic Propellants: Particle Formation Energy and Imaging Analyses," AIAA 2002-4092, presented at the 38th AIAA/ASME/SAE Joint Propulsion Conference, Indianapolis, IN, July 2002.

35 Palaszewski, B., " Solid Hydrogen Experiments For Atomic Propellants: Image Analyses," AIAA 20013233, presented at the 37th AIAA/ASME/SAE Joint Propulsion Conference, Salt Lake City, UT, July 2001.

36 Palaszewski, B., "Solid Hydrogen Experiments for Atomic Propellants," AIAA 2000-3855, presented at the 36th AIAA/ASME/SAE Joint Propulsion Conference, Huntsville, AL, July 2000.

37 Palaszewski, B., "Solid Hydrogen Testing and Analyses for Atomic Rocket Propulsion," presented to the Propulsion Engineering Research Center (PERC) 11th Annual Symposium on Propulsion, The Atherton Hotel, State College, PA, November 18-19, 1999. 
38 Palaszewski, B., "Launch Vehicle Performance for Bipropellant Propulsion using Atomic Propellants with Oxygen," AIAA 99-2837, presented at the 35th AIAA/ASME/SAE Joint Propulsion Conference, Los Angeles, CA, June 1999.

39 Palaszewski, B., "Atomic Propellants for Aerospace Propulsion Systems: Solid Hydrogen Experiments and Vehicle Analyses," presented at the 1999 USAF High Energy Density Materials Contractors Conference, Cocoa Beach, FL, June 8-10, 1999.

40 Palaszewski, B., Ianovski, L., and Carrick, P., "Propellant Technologies: Far Reaching Benefits for Aeronautical and Space Vehicle Propulsion," in the Special Edition of the AIAA Journal of Propulsion and Power, September/October 1998, pp. 641-648.

41 Palaszewski, B., "Launch Vehicle Performance with Solid Particle Feed Systems for Atomic Propellants," AIAA 98-3736, NASA TM 1998-208498, presented at the 34th AIAA/ASME/SAE Joint Propulsion Conference, Cleveland, OH, July 1998.

42 Palaszewski, B., "Atomic Hydrogen Propellants: Historical Perspectives and Future Possibilities," NASA-Lewis Research Center, AIAA 93-0244, NASA TM-106053, presented at the 31st AIAA Aerospace Science Meeting, Reno, NV, January 11-14, 1993. 


\section{Appendix A}

Rocket Specific Impulse, Performance, RX-M Analyses

Calculations were completed to determine the rocket engine performance for a range of ozone, atomic hydrogen and molecular hydrogen fractions. This was a way to assess the effect of RXM's "A" propellant (which, as noted in the main text, was assumed to describe the percent of atomic hydrogen in a solid molecular hydrogen matrix). The results of these calculations indicate that the levels of the movie's "A" propellant (A12, A14, A16) only produce a specific impulse of approximately $6.7 \mathrm{~km} / \mathrm{s}(700 \mathrm{~s})$ to $7.8 \mathrm{~km} / \mathrm{s}(800 \mathrm{~s})$.

NOTE: All calculations are for oxidizer-to-fuel $(\mathrm{O} / \mathrm{F})$ ratios of 0.5 to 5 .

- Ozone and atomic hydrogen $\left(100 \% \mathrm{H}, 00 \% \mathrm{H}_{2}\right)$

- Ozone and atomic hydrogen $\left(75 \% \mathrm{H}, 25 \% \mathrm{H}_{2}\right)$

- Ozone and atomic hydrogen $\left(50 \% \mathrm{H}, 50 \% \mathrm{H}_{2}\right)$

- Ozone and atomic hydrogen $\left(25 \% \mathrm{H}, 75 \% \mathrm{H}_{2}\right)$

- Ozone and atomic hydrogen $\left(15 \% \mathrm{H}, 85 \% \mathrm{H}_{2}\right)$

- Ozone and hydrogen $\left(00 \% \mathrm{H}, 100 \% \mathrm{H}_{2}\right)$ 


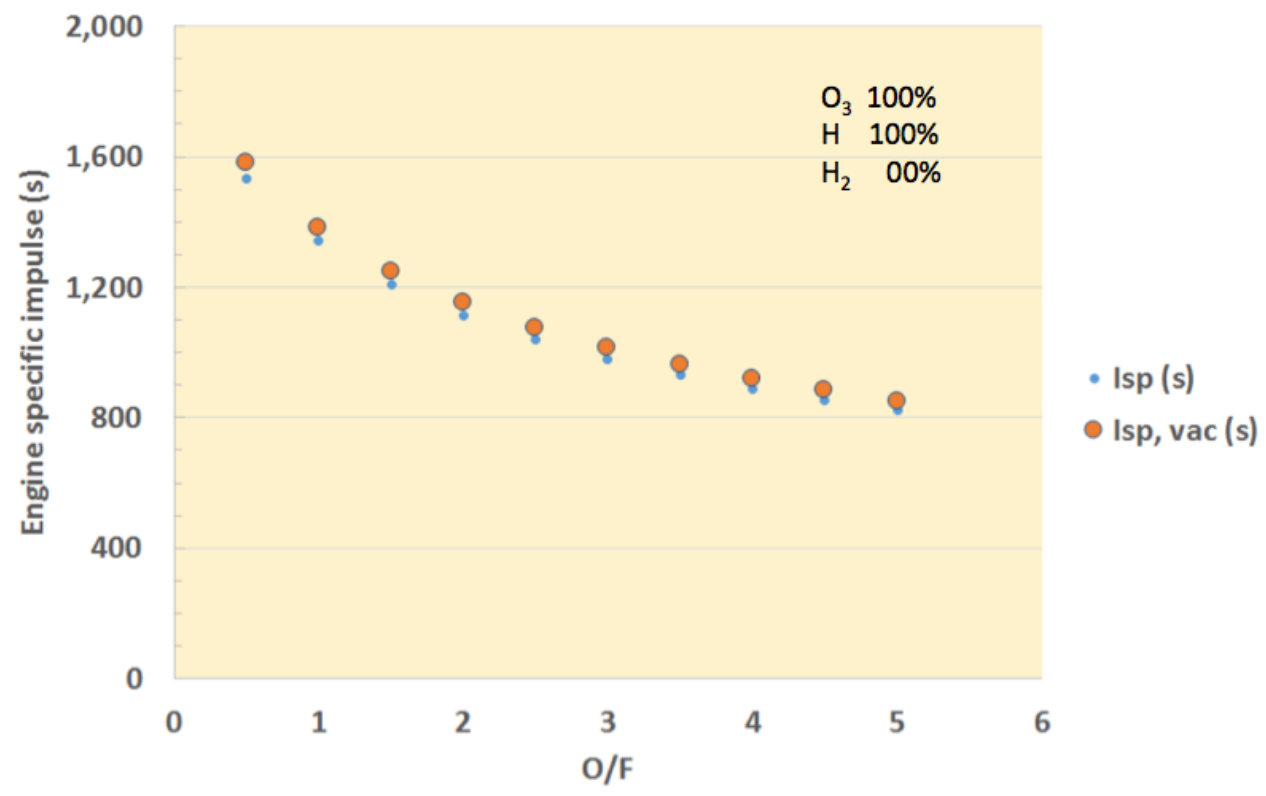

Figure A-1. RX-M engine specific impulse as a function of oxidizer-to-fuel ratio for $100 \%$ ozone, $100 \%$ atomic hydrogen and $0 \%$ molecular hydrogen.

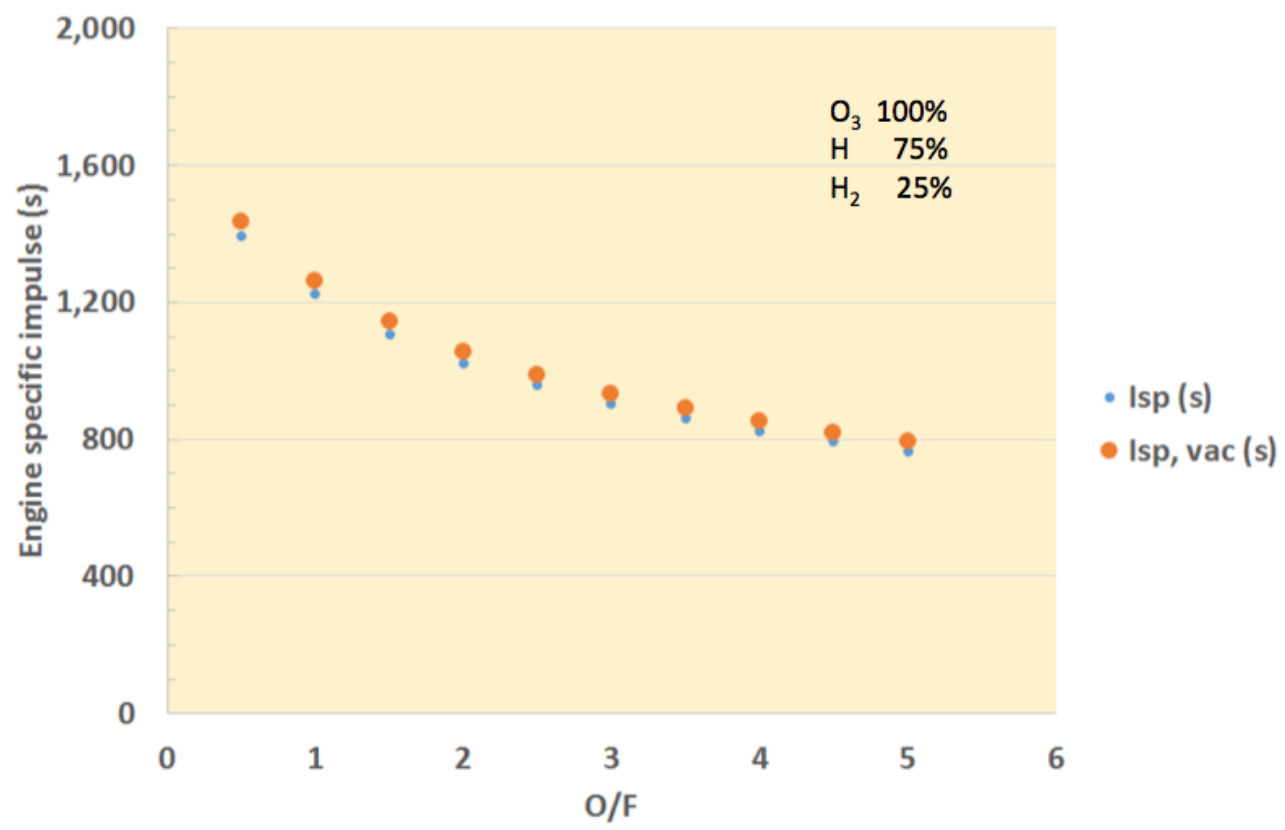

Figure A-2. RX-M engine specific impulse as a function of oxidizer-to-fuel ratio for $100 \%$ ozone, $75 \%$ atomic hydrogen and $25 \%$ molecular hydrogen. 


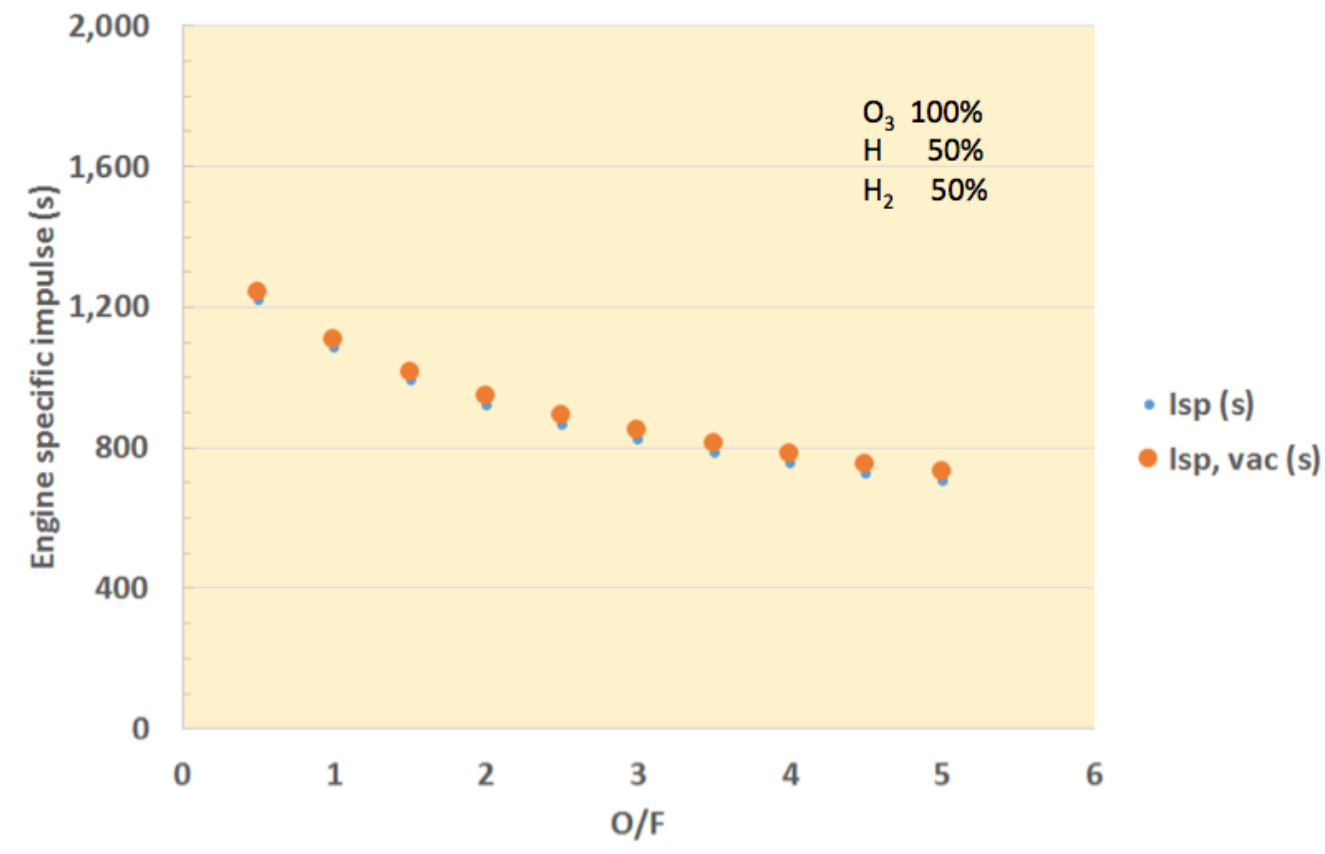

Figure A-3. RX-M engine specific impulse as a function of oxidizer-to-fuel ratio for $100 \%$ ozone, $50 \%$ atomic hydrogen and $50 \%$ molecular hydrogen.

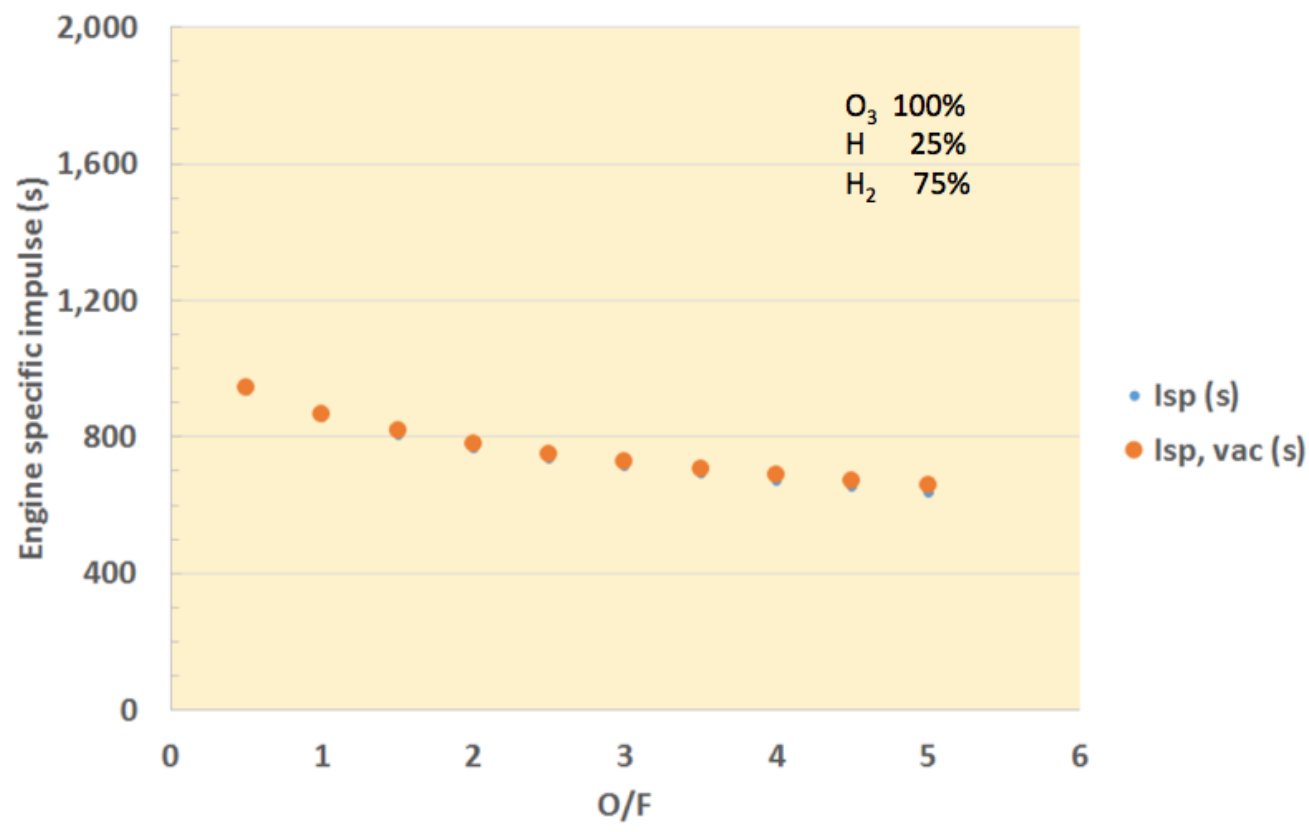

Figure A-4. RX-M engine specific impulse as a function of oxidizer-to-fuel ratio for $100 \%$ ozone, $25 \%$ atomic hydrogen and $75 \%$ molecular hydrogen. 


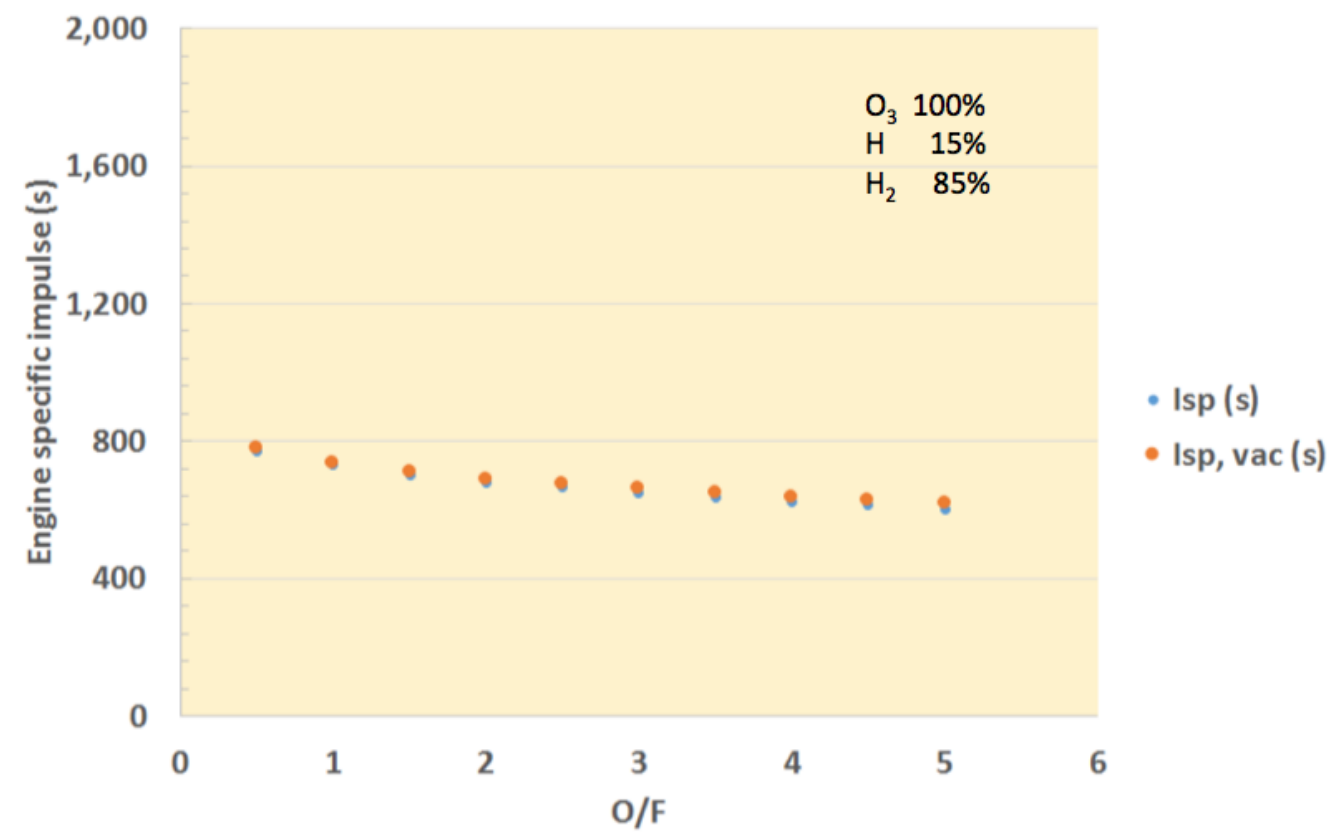

Figure A-5. RX-M engine specific impulse as a function of oxidizer-to-fuel ratio for $100 \%$ ozone, $15 \%$ atomic hydrogen and $85 \%$ molecular hydrogen.

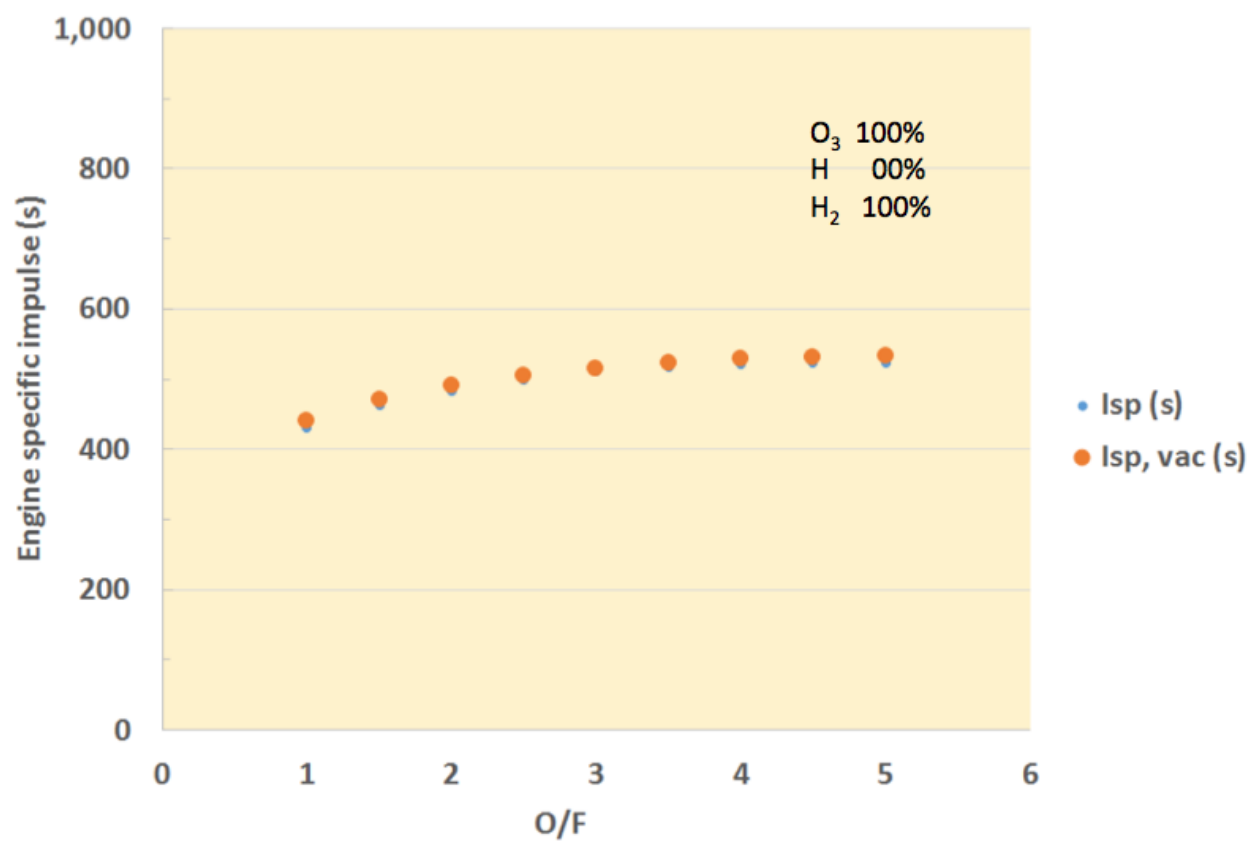

Figure A-6. RX-M engine specific impulse as a function of oxidizer-to-fuel ratio for $100 \%$ ozone, $00 \%$ atomic hydrogen and $100 \%$ molecular hydrogen. 


\section{Appendix B:}

\section{Propellant Chemistry}

Fritz Zwicky pioneered "general morphological analysis" in examining types of rocket engines and a range of propellants (Biblio. 12, 13, 14). Beginning in 1943, proposals for what Zwicky termed "meta-chemistry" circulated within Aerojet Engineering Corporation. Zwicky described meta-chemistry as dealing "with the study, production and the use of quantum mechanically metastable particles, molecules or states of matter in general" More recently, such propellants have been referred to as "HEDM", high-energy density materials.

Zwicky investigated metachemistry propellants in an effort to avoid what he termed the "carbon dilemma" of hydrocarbon fuels, i.e., fuels that included carbon in the chemistry were therefore subject to lower specific impulses because carbon atoms are heavier than hydrogen atoms and the carbon might not completely combust producing $\mathrm{CO}$ instead of $\mathrm{CO} 2$. (Biblio. 12, 13,14) As an example of what could be achieved with metachemistry, Zwicky noted that the reaction of monatomic hydrogen with monatomic hydrogen $(\mathrm{H}+\mathrm{H}=\mathrm{H} 2)$ liberated 51.9 $\mathrm{kcal} / \mathrm{g}$ as compared with 0.63 and $1.51 \mathrm{kcal} / \mathrm{g}$ for TNT and nitroglycerine respectively. Zwicky said that the reaction $\mathrm{H}+\mathrm{H}=\mathrm{H} 2$ gave a limiting specific impulse of $21 \mathrm{~km} / \mathrm{s}$. (Biblo. 13)

Beginning in 1952 with a series of articles in Collier's magazine, Wernher von Braun and colleagues publicized the idea of a crewed lunar vehicle that was over $48 \mathrm{~m}$ long and about $33 \mathrm{~m}$ wide with a mass of over 3.9 Mkg (4,370 tons) propelled by a battery of thirty rocket motors providing a total thrust of $3.6 \mathrm{MN}$ (407 tons) of thrust (Biblio. 15) The rocket motors were to use a combination of hydrazine and nitric acid (a combination that would later be used with modifications in the Soviet R-16 launch vehicle).

Around the same time that monatomic hydrogen was being mentioned as a possible propellant was the idea of using ozone as an oxidizer. Willy Ley described some of the advantages of using ozone as an oxidizer in his series of books that began with Rockets in 1944. Ley wrote that "To all intents and purposes ozone is a kind of concentrated oxygen. It has a higher specific gravity: a tank that holds 6 pounds of liquid oxygen holds almost 10 pounds of liquid ozone. Liquid ozone not only provides more oxygen in a given volume (and for a given tank weight), but also has some advantages as to temperature. The boiling point of liquid oxygen is - 183 degrees centigrade, that of liquid ozone -119 degrees centigrade" (Biblio. 16).

Ley went on to point out that "In addition to higher density and higher boiling point ozone has another advantage which is reminiscent of the decomposition of hydrogen peroxide. The atoms which normally form the oxygen molecule can rearrange themselves into ozone molecules only by absorbing energy ( 719 calories per gram) ... When ozone is used as an oxidizer for combustion, it reverts to ordinary oxygen, thereby releasing the energy it had originally absorbed. This energy release naturally would show up as a higher exhaust velocity; calculation shows that a fuel burned with ozone would produce an exhaust velocity some 10 per cent higher than that produced by the same fuel burned with oxygen" (Biblio. 16).

Studies of ozone as an oxidizer were more than just speculation in popular books. In the late 1940s, scientists at the Flight Propulsion Research Laboratory of the National Advisory Committee for Aeronautics (NACA) (now NASA's John H. Glenn Research Center at Lewis Field) began studying the theoretical performance of some rocket propellants containing hydrogen, nitrogen and oxygen, specifically liquid ozone. With hydrogen as the fuel, liquid ozone gave the highest specific impulse, beating out liquid oxygen and 100-percent hydrogen peroxide (Biblio. 17).

Researchers at Princeton University investigated various mixtures of liquid ozone in liquid oxygen with successful runs being made in the $10 \%$ to $15 \%$ range. As the Princeton researchers were aware (and Ley also noted), ozone is an unstable compound; in fact, the Princeton researchers "confirmed the highly brisant character" of the ozone reactions that occurred during detonation tests (Biblio. 19) Ozone concentrations approaching 28\% were explosive.19 NASA researchers found that "Explosions were encountered when equipment or procedure permitted ozone to concentrate locally" (Biblio. 20). 
There have been several papers published on the reaction of hydrogen atoms (including atomic hydrogen) with ozone (Biblio. 21-24). Observed reactions include (Biblio. 22, 24):

$$
\begin{aligned}
& \mathrm{H}+\mathrm{O} 3 \rightarrow \mathrm{OH}+\mathrm{O} 2 \\
& \mathrm{H}+\mathrm{O} 3 \rightarrow \mathrm{HO} 2+\mathrm{O}
\end{aligned}
$$

